\title{
CONSTRUCTIVE-FUNCTIONAL ANALYSIS AND CALCULATION OF FLOW CONTROL VALVES
}

\author{
Georgiana Alexandra MOROȘANU ${ }^{1}$, Răzvan CRĂCIUN ${ }^{1}$, \\ Nicușor BAROIU 1
}

${ }^{1}$ Department of Manufacturing Engineering, "Dunărea de Jos” University of Galați, România email: craciun_razvan1@yahoo.com

\begin{abstract}
In hydraulic installations, the flow regulation is performed in two ways: volume regulation (by variable flow pump) and resistive regulation, with the help of the flow regulation equipment. The second variant, although with lower energy efficiency, is most often preferred in small and medium power installations, due to the constructional simplicity and easy maneuverability of the equipment, as well as the ease of performing operation control. The paper presents the construction of the most important devices for resistive flow regulation, the mode of operation and installation in the structure of the systems, as well as certain elements of their calculation.
\end{abstract}

KEYWORDS: flow control valve, volume control, resistive control, flow.

\section{INTRODUCTION}

Flow control equipment is designed to adjust the speed or the rotation of hydraulic engines by changing the flow administered to them. The flow control can be done in two ways: volume control and resistive control [1], [4].

Volume control, Figure 1, consists in introducing a flow of motor agent into the hydraulic motor modified by a hydraulic pump $(P)$. At this setting, the pump is of the variable flow type. The flow discharged by the pump coincides with the flow administered to the hydromotor, the volumes of oil discharged from the pump being the direct capacity of the hydromotor.
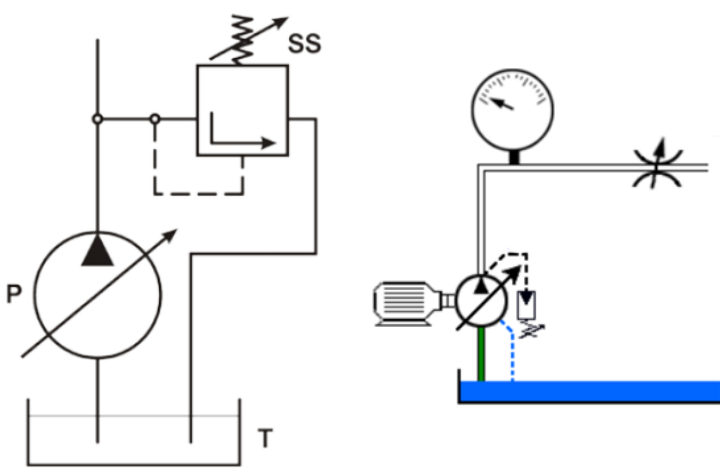

Fig. 1. The flow control - volume control [1]: $S S$ - pressure relief valve; $T$ - tank; $P$ - pump with variable flow.
Resistive regulation of the flow, Figure 2, uses devices known as flow control valves. In hydrostatic schemes, they can be used simply, in which case they are only adjustable hydraulic resistances, and the change of flow being done by increasing or decreasing a slot of a certain shape [1].
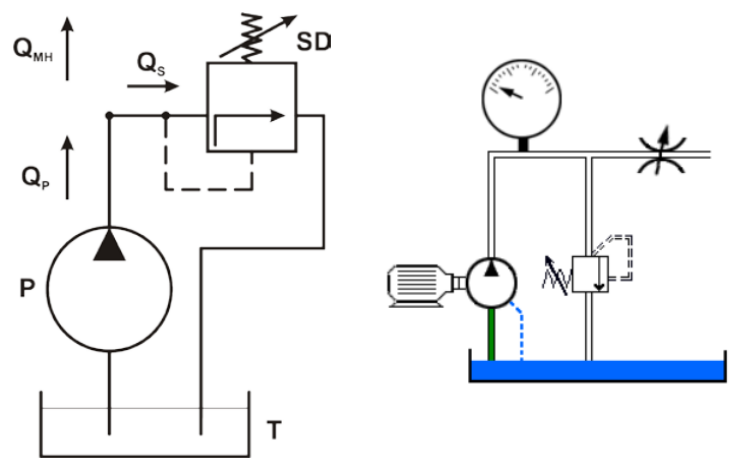

Fig. 2. The flow control - resistive control [1]: $S D$ - pressure reducing valve; $T$ - tank; $P$ - pump with constant flow; $Q_{M H}$ - variable flow required for hydraulic motor; $Q_{p}$ - flow discharge by pump; $Q_{S}$ - the difference between $Q_{P}$ and $Q_{M H}$.

There are several criteria for classifying the flow control valves. For example, according to the construction criterion, the flow control valves are classified according to Figure 3. 


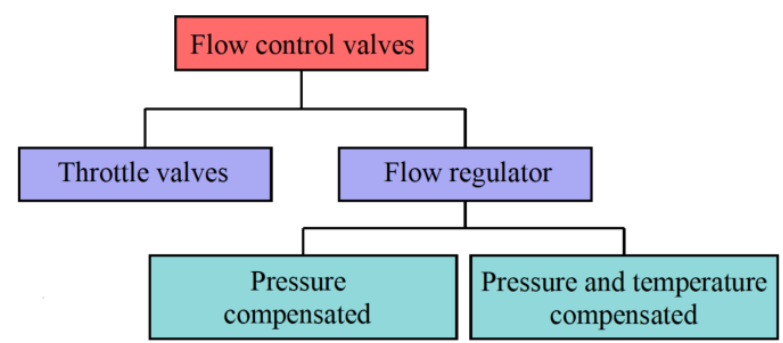

Fig. 3. Classification of flow control valves [2]

Depending on how the installation is installed, the flow control valves can be [1]:

- trail flow control valves - mounted on pipes;

- panel flow control valves - mounted on modular boards or blocks.

In hydrostatic schemes, trail flow control valves, Figure 4, can be used simply, in which case there are only adjustable hydraulic resistances, the flow change being done by increasing or decreasing a slot of a certain shape [5-8].

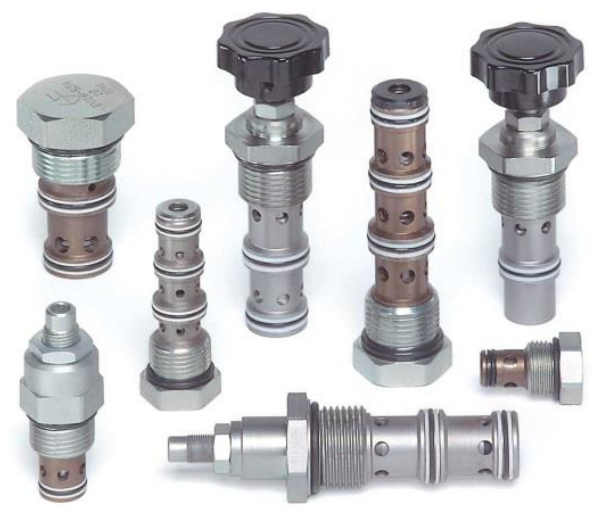

Fig. 4. Trail flow control valves [3]

Trail flow control valves, Figure 5, make the modification of the oil passage surface by screwing the bushing (2) on the body (1).

The flow control valve controls and adjusts the flow for the direction of flow marked with an arrow. It is provided with a directional valve whose plate (3) moves, allowing the free (non-sealed) passage of the hydraulic agent, in the opposite direction to the arrows shown.

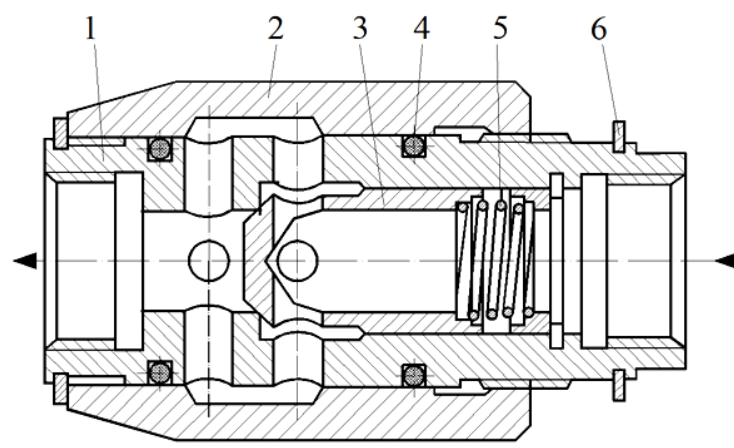

Fig. 5. Trail flow control valve [1]:

1 - body; 2 - adjusting element; 3 - plate; 4 - O-ring; 5 - spring; 6 - stroke limiter.
Panel flow control valve, Figure 6, makes the modification of the oil passage surface, respectively of the droselization slot by the axial displacement of the plunger (4), which constitutes the adjusting element, with respect to the body (3).

They are also fitted with a direction valve (5), which allows the free movement of the hydraulic agent in the opposite direction to the direction controlled by the flow control valve (direction of the arrow).

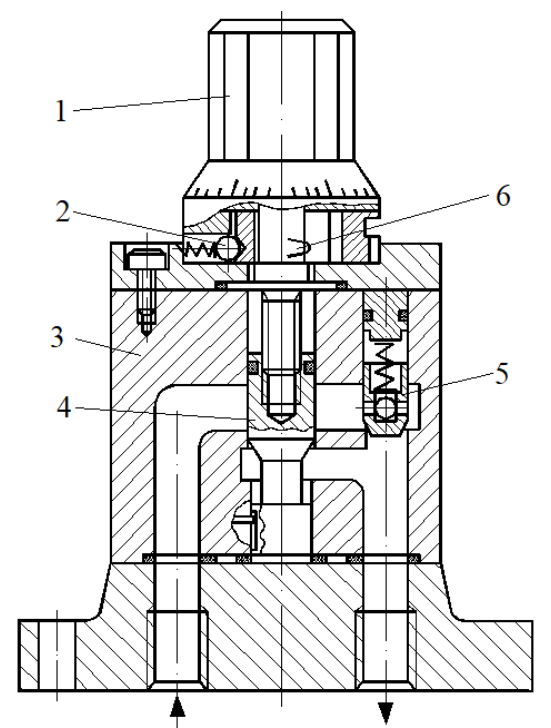

Fig. 6. Panel flow control valve [1]: 1 - graduated drum; 2 - indexing body with ball and spring; 3 - body; 4 - adjusting element; 5 - directional valve; 6 - element for counting rotations.

The improvement of the movement stability of hydraulic engines in structures fed by constant flow pumps is done with flow (speed) regulator constructions that are obtained if a flow regulator is attached to the simple flow control valve, Figure 7.

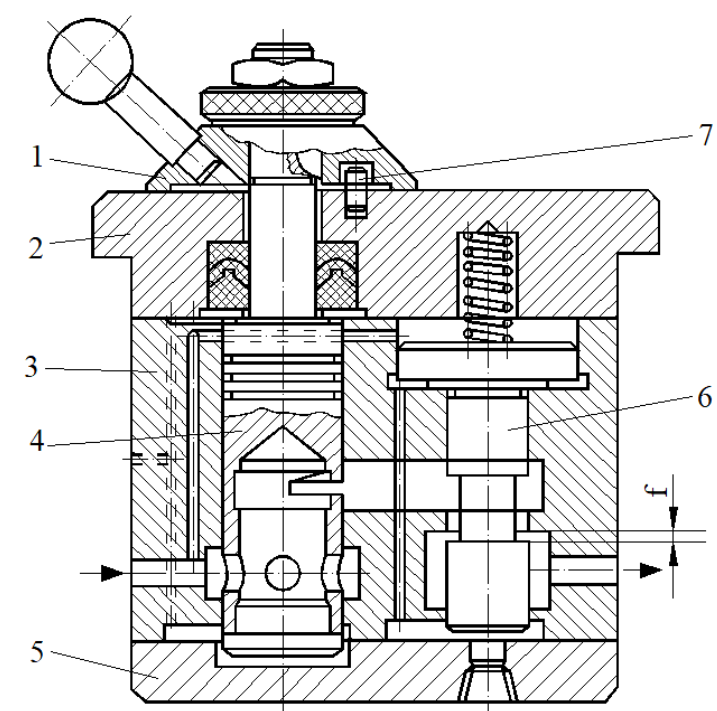

Fig. 7. Flow regulator [1]:

1 - graduated drum; 2 - lid; 3 - body; 4 - adjusting element; 5 - lid; 6 -flow regulator; 7 - stroke limiter. 


\section{CHARACTERISTIC CURVES OF FLOW CONTROL VALVES AND FLOW REGULATORS}

Figure 8 shows typical characteristics of flow control valves. The characteristics show the variation of the flow with respect to the differential pressure along with the flow control valve when it is left completely open. These characteristics are assumed to be nonlinear. Some manufacturers choose to present test data in linear format with unequal increments on the $\mathrm{Y}$ axis [2].

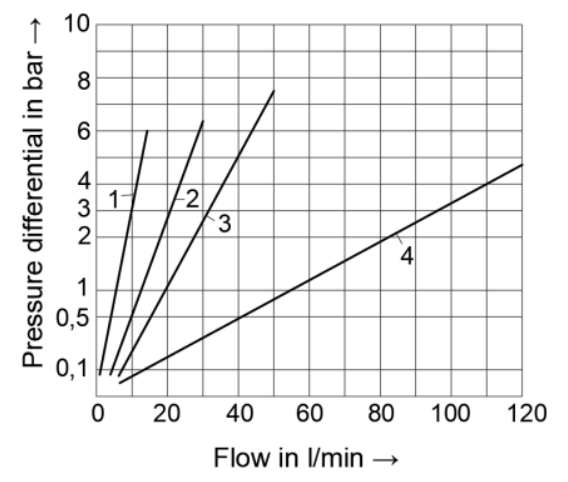

a.

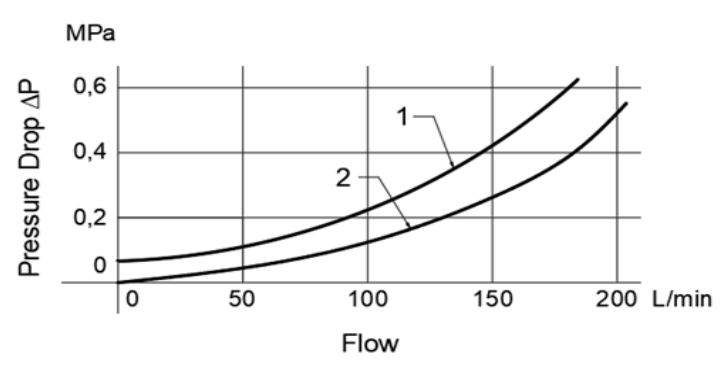

b.

Fig. 8. Characteristic curves of flow control valves [2].

Pressure Compensation at Constant Temperature

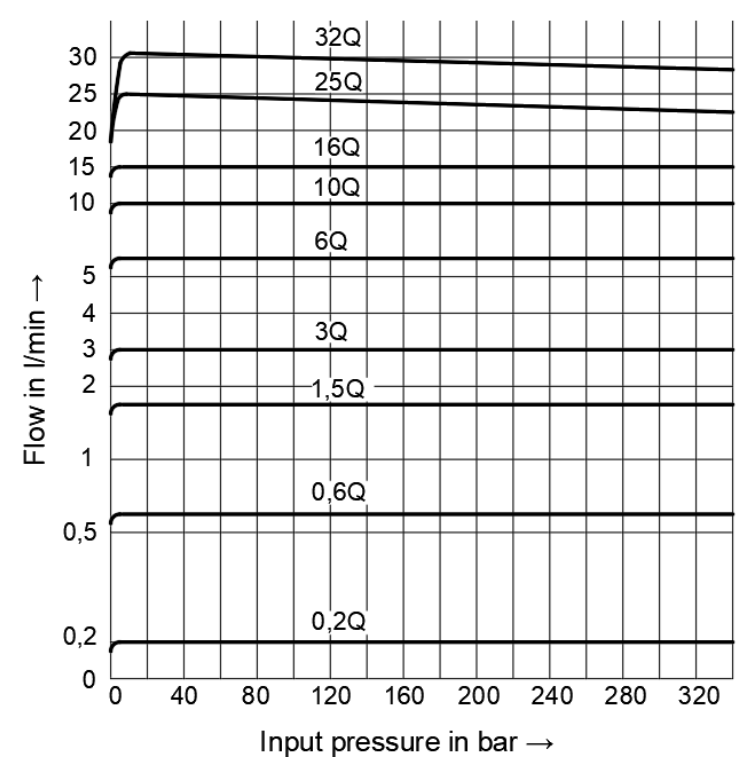

$a$.

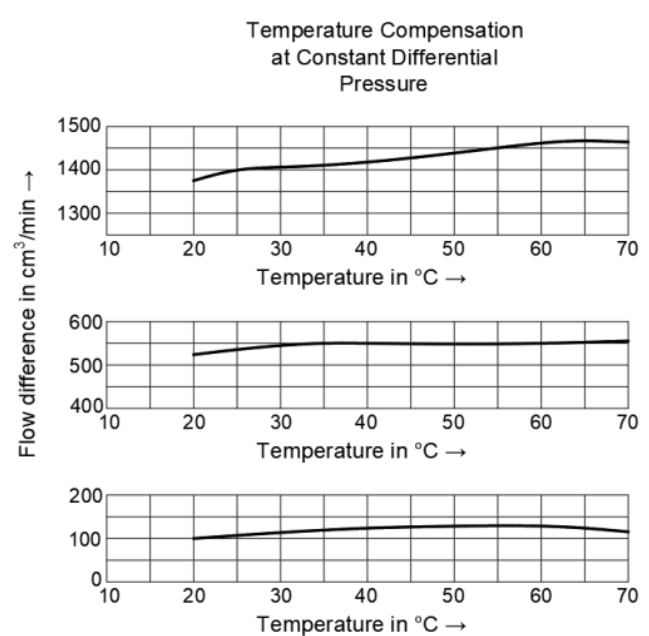

$b$.

Fig. 9. Characteristics of flow regulators [2].

Figure 9 shows typical characteristics for a flow regulator compensated with pressure and temperature [2].

\section{HYDRAULIC FLOW CONTROL VALVES INSTALLATION SOLUTIONS}

The hydraulic installation solutions of the flow control valves are presented in Figure 10.a $\div$ 10.f. These are:

- flow control valve on hydromotor intake, Figure 10.a;

- flow control valve on the exhaust from the hydromotor, Figure 10.b;

- bypass flow control valve, Figure 10.c;

- three-way regulator on the hydromotor intake, Figure 10.d;

- two-way regulator on the hydromotor exhaust, Figure 10.e;

- mixed regulator, Figure 10.f;

Installing a flow control valve on a hydromotor intake, Figure 10.a, is a simple solution, allowing the engine to work at the actual pressure dictated by the load. However, the constancy of the useful flow $Q_{u t}=Q-q$, at the variation of the load $S$ is not ensured, losing total speed control in case of a negative load $-S$.

In the case of the flow control valve on the exhaust from the hydromotor, Figure 10.b, the speed control is maintained when the negative load occurs, but it constantly demands the system at the maximum pressure of the safety valve.

The installation of a bypass flow control valve, Figure 10.c, is an energy efficient solution because the discharge of the excess flow $q$ is not done through the safety valve at its maximum control pressure, but through the flow control valve itself, at the effective pressure given by the load $S$.

In most applications, when the valve opens and the resistance due to fluids flow decreases, the pressure drops across the valve [9], [10]. 
A linear inherent curve will in general resemble a quick opening characteristic.

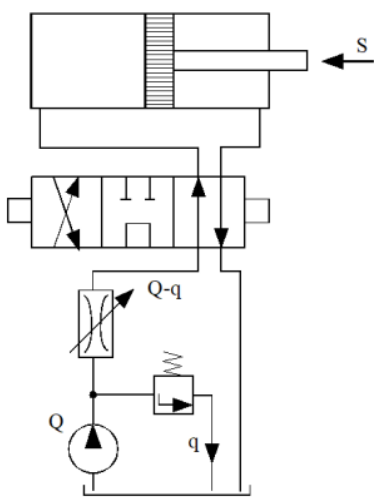

a.

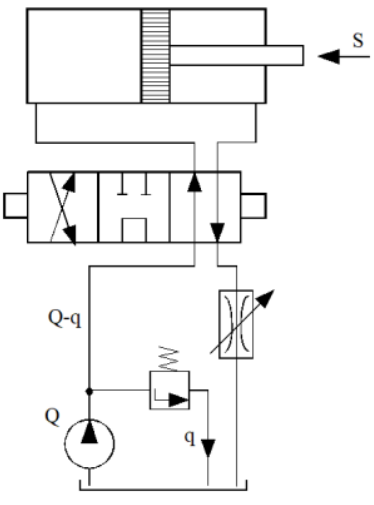

$b$.
Fig. 10. Hydraulic installation of flow control valves [1]: a. flow control valve on hydromotor intake; b. flow control valve on the exhaust from the hydromotor.

However, the variation of the useful flow with the load is even more pronounced than in the cases presented in Figures 10.a and 10.b.

The installation of a three-way regulator on the hydromotor intake, Figure 10.d, is a solution with good energy efficiency (the discharge of the excess flow $q$ is done through the stabilizer valve at the given load pressure).

Unlike the case shown in Figure 10.a, it is ensured that the useful flow $Q_{u t}$ is kept approximately constant at the variation of the load $\mathrm{S}$ in a positive direction.

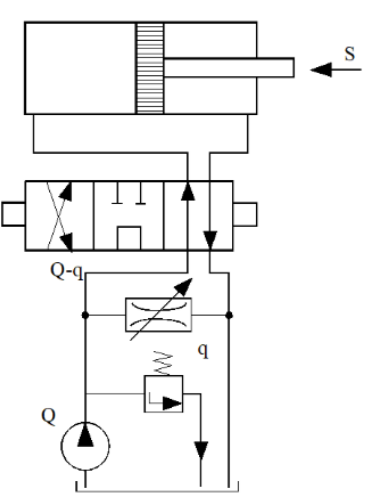

$c$.

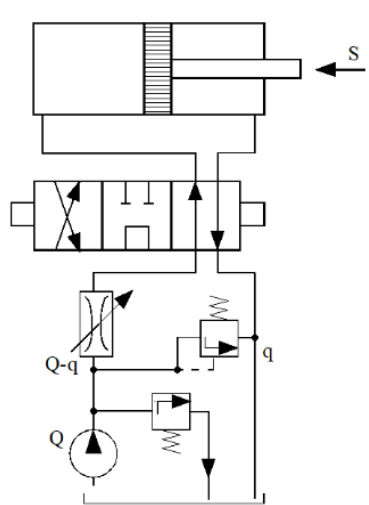

$d$.
Fig. 10. Hydraulic installation of flow control valves [1]: c. bypass flow control valve; $d$. three-way regulator on the hydromotor intake.

The two-way regulator on the hydromotor exhaust, Figure 10.e, although with lower energy efficiency than in the previous case (the system is required, the flow $q$ passing through the safety valve), is recommended for both positive and negative loads.

The mixed regulator, Figure 10.f, combines the qualities of the regulators presented in the schemes from Figures 10.d and 10.e, but posing difficult problems of constructive nature.

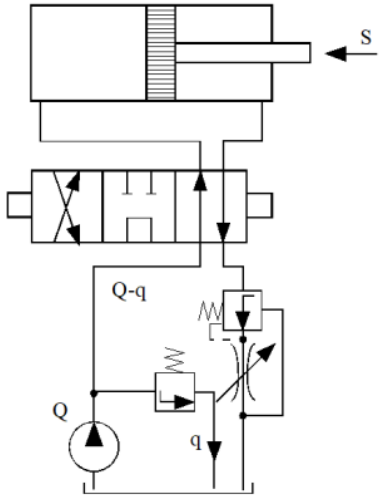

$e$.

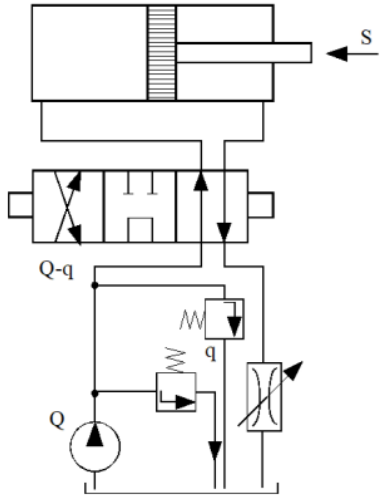

$f$.
Fig. 10. Hydraulic installation of flow control valves [1]: e. two-way regulator on the hydromotor exhaust; f. mixed regulator.

\section{FLOW CONTROL VALVE CALCULATION}

The hydraulic calculation of the flow control valve refers to the determination of the value of the flow $Q$ adjusted with the help of the respective device. The flow equation of a flow control valve is of the form:

$$
Q=\alpha \cdot k \cdot S \cdot \sqrt{\Delta p}
$$

where:

- $\alpha$ is a flow coefficient, $\alpha=0.6 . .0 .7$;

- $k$ - constant depending on the type of hydraulic fluid (for mineral oils $=0.885$ ):

$$
k=\sqrt{\frac{2}{\rho}} ;
$$

- $\Delta p$ - pressure drop on the flow control valve, $\Delta p=1.5 \ldots 3$ bar;

- $S$ - the surface of the fluid passage slot.

Theoretically, the flow rate through a flow control valve varies linearly with the size of the passage surface, Figure 11. However, it is basically corrected with a value due to the viscous friction of the hydromotor agent during the flow.

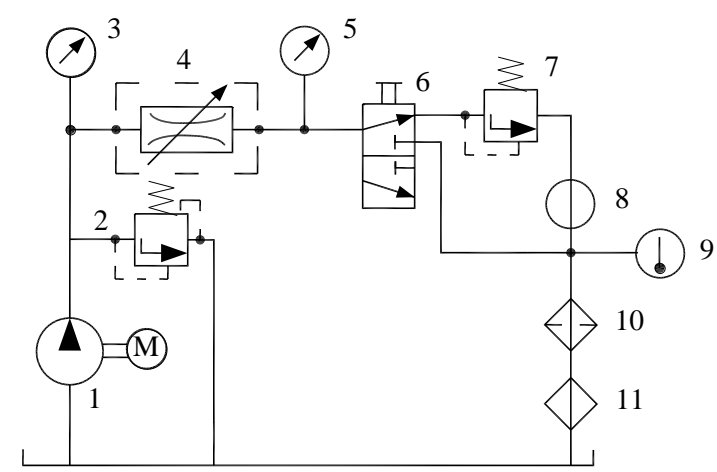

Fig. 11. Stand [1]: 1 - pump; 2, 7 - pressure control valve; 3, 5 - manometer; 4 - flow control valve; 6 - directional control valve; 8 - flow meter; 9 - thermometer; 10 - filter; 11 - heat exchanger. 
Therefore, the input data for the calculation of the flow $Q$ in relation to the increase of the diameter $D$ and a pressure drop of $\Delta p=1.5$ bar are presented in Table 1.

Table 1. The input data for the calculation of the flow $Q$ in relation to the increase of the diameter $D$ and $a$ pressure drop of $\Delta p=1.5 \mathrm{bar}$

\begin{tabular}{|c|c|c|c|c|c|}
\hline No. & $\boldsymbol{\alpha}$ & $\boldsymbol{\kappa}$ & $\boldsymbol{\Delta p}[\mathbf{b a r}]$ & $\mathbf{D}[\mathbf{m m}]$ & $\mathbf{Q}[\mathbf{1} / \mathbf{m i n}]$ \\
\hline 1 & 0.6 & 0.885 & 1.5 & 20 & 12.26 \\
\hline 2 & 0.6 & 0.885 & 1.5 & 21 & 13.52 \\
\hline 3 & 0.6 & 0.885 & 1.5 & 22 & 14.83 \\
\hline 4 & 0.6 & 0.885 & 1.5 & 23 & 16.21 \\
\hline 5 & 0.6 & 0.885 & 1.5 & 24 & 17.65 \\
\hline 6 & 0.6 & 0.885 & 1.5 & 25 & 19.15 \\
\hline 7 & 0.6 & 0.885 & 1.5 & 26 & 20.72 \\
\hline 8 & 0.6 & 0.885 & 1.5 & 27 & 22.34 \\
\hline 9 & 0.6 & 0.885 & 1.5 & 28 & 24.03 \\
\hline 10 & 0.6 & 0.885 & 1.5 & 29 & 25.77 \\
\hline
\end{tabular}

The results are graphically presented in Figure 12.

$\square[\mathbf{Q} / \mathbf{m i n}] \quad \mathrm{D}[\mathrm{mm}]$

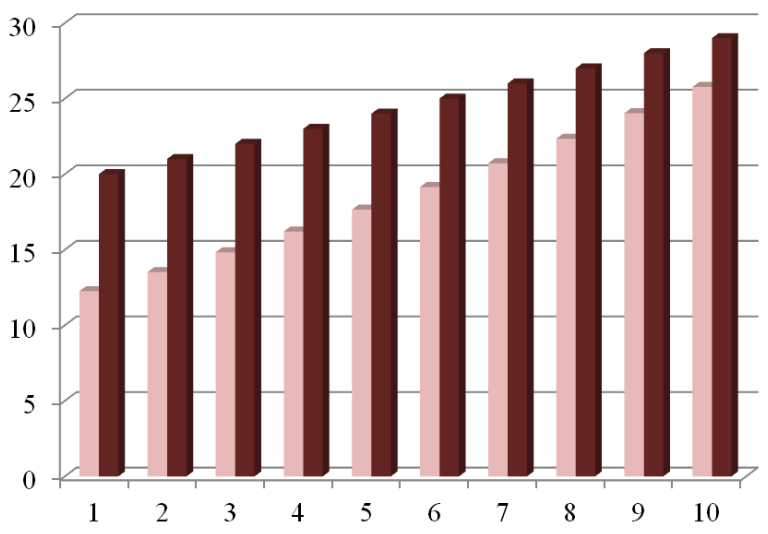

Fig. 12. The variation of the flow $Q$ in relation to the increase of the diameter $D$ and a pressure drop of $\Delta p=1.5 \mathrm{bar}$

The input data for the calculation of the flow $Q$ in relation to the same values of diameter $D$ and a pressure drop of $\Delta p=2 \mathrm{bar}$ are presented in Table 2 and graphically in Figure 13.

Table 2. The input data for the calculation of the flow $Q$ in relation to the same values of diameter $D$ and $a$ pressure drop of $\Delta p=2$ bar

\begin{tabular}{|c|c|c|c|c|c|}
\hline No. & $\boldsymbol{\alpha}$ & $\mathbf{\kappa}$ & $\boldsymbol{\Delta p}[\mathbf{b a r}]$ & $\mathbf{D}[\mathbf{m m}]$ & $\mathbf{Q}[\mathbf{l} / \mathbf{m i n}]$ \\
\hline 1 & 0.6 & 0.885 & 2 & 20 & 14.16 \\
\hline 2 & 0.6 & 0.885 & 2 & 21 & 15.61 \\
\hline 3 & 0.6 & 0.885 & 2 & 22 & 17.13 \\
\hline 4 & 0.6 & 0.885 & 2 & 23 & 18.72 \\
\hline 5 & 0.6 & 0.885 & 2 & 24 & 20.38 \\
\hline 6 & 0.6 & 0.885 & 2 & 25 & 22.12 \\
\hline 7 & 0.6 & 0.885 & 2 & 26 & 23.92 \\
\hline 8 & 0.6 & 0.885 & 2 & 27 & 25.80 \\
\hline 9 & 0.6 & 0.885 & 2 & 28 & 27.74 \\
\hline 10 & 0.6 & 0.885 & 2 & 29 & 29.76 \\
\hline
\end{tabular}

$\mathrm{Q}[\mathbf{l} / \mathbf{m i n}] \quad \mathrm{D}[\mathrm{mm}]$

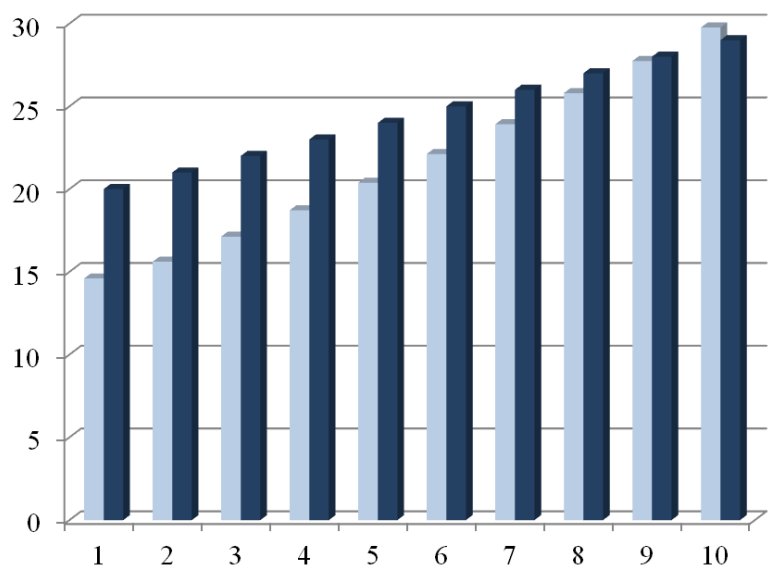

Fig. 13. The variation of the flow $Q$ in relation to the increase of the diameter $D$ and a pressure drop of $\Delta p=2$ bar

The input data for the calculation of the flow $Q$ in relation to the same values of diameter $D$, to the increase of pressure drop of $\Delta p=2.5 \mathrm{bar}$ and to the increase of flow coefficient $\alpha$, are presented in Table 3 and graphically in Figure 14.

Table 3. The input data for the calculation of flow $Q$ in relation to the same values of diameter, an increase

of pressure drop and an increase of flow coefficient

\begin{tabular}{|c|c|c|c|c|c|}
\hline No. & $\boldsymbol{\alpha}$ & $\boldsymbol{\kappa}$ & $\boldsymbol{\Delta p}[\mathbf{b a r}]$ & $\mathbf{D}[\mathbf{m m}]$ & $\mathbf{Q}[\mathbf{l} / \mathbf{m i n}]$ \\
\hline 1 & 0.7 & 0.885 & 2.5 & 20 & 18.46 \\
\hline 2 & 0.7 & 0.885 & 2.5 & 21 & 20.36 \\
\hline 3 & 0.7 & 0.885 & 2.5 & 22 & 22.34 \\
\hline 4 & 0.7 & 0.885 & 2.5 & 23 & 24.42 \\
\hline 5 & 0.7 & 0.885 & 2.5 & 24 & 26.59 \\
\hline 6 & 0.7 & 0.885 & 2.5 & 25 & 28.85 \\
\hline 7 & 0.7 & 0.885 & 2.5 & 26 & 31.20 \\
\hline 8 & 0.7 & 0.885 & 2.5 & 27 & 33.65 \\
\hline 9 & 0.7 & 0.885 & 2.5 & 28 & 36.19 \\
\hline 10 & 0.7 & 0.885 & 2.5 & 29 & 38.82 \\
\hline
\end{tabular}

$\square \mathbf{Q}[\mathbf{l} / \mathbf{m i n}] \quad \mathbf{D}[\mathbf{m m}]$

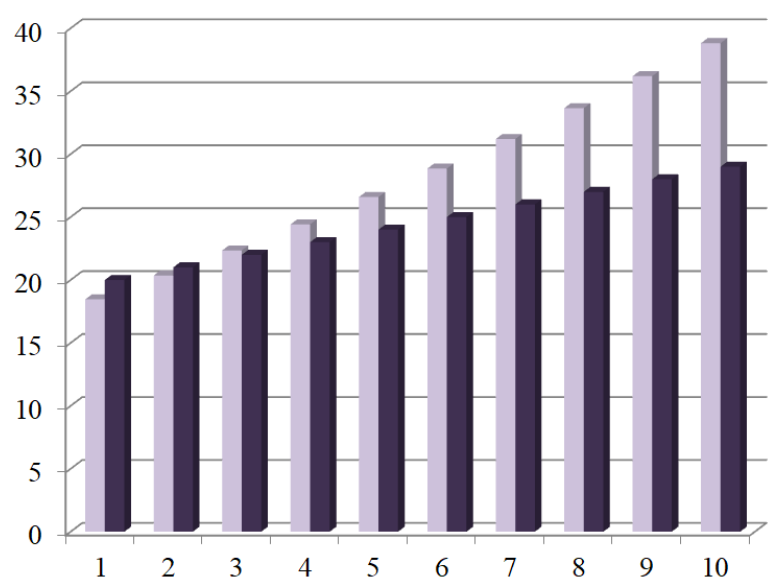

Fig. 14. The variation of the flow $Q$ in relation to the increase of the diameter $D$, to the increase of pressure drop $\Delta p$ and to the increase of flow coefficient $\alpha$ 
The input data for the calculation of the flow $Q$ in relation to the same values of diameter $D$, the same flow coefficient $\alpha$ and the increase of pressure drop of $\Delta p=3$ bar are presented in Table 4 and graphically in Figure 15 .

Table 4. The input data for the calculation of flow $Q$ in relation to the same values of diameter, an increase

of pressure drop and an increase of flow coefficient

\begin{tabular}{|c|c|c|c|c|c|}
\hline No. & $\boldsymbol{\alpha}$ & $\mathbf{\kappa}$ & $\boldsymbol{\Delta p}[\mathbf{b a r}]$ & $\mathbf{D}[\mathbf{m m}]$ & $\mathbf{Q}[\mathbf{l} / \mathbf{m i n}]$ \\
\hline 1 & 0.7 & 0.885 & 3 & 20 & 20.23 \\
\hline 2 & 0.7 & 0.885 & 3 & 21 & 22.30 \\
\hline 3 & 0.7 & 0.885 & 3 & 22 & 24.47 \\
\hline 4 & 0.7 & 0.885 & 3 & 23 & 26.75 \\
\hline 5 & 0.7 & 0.885 & 3 & 24 & 29.12 \\
\hline 6 & 0.7 & 0.885 & 3 & 25 & 31.60 \\
\hline 7 & 0.7 & 0.885 & 3 & 26 & 34.18 \\
\hline 8 & 0.7 & 0.885 & 3 & 27 & 36.86 \\
\hline 9 & 0.7 & 0.885 & 3 & 28 & 39.64 \\
\hline 10 & 0.7 & 0.885 & 3 & 29 & 42.52 \\
\hline
\end{tabular}

$Q[\mathbf{l} / \mathbf{m i n}] \quad D[\mathrm{~mm}]$

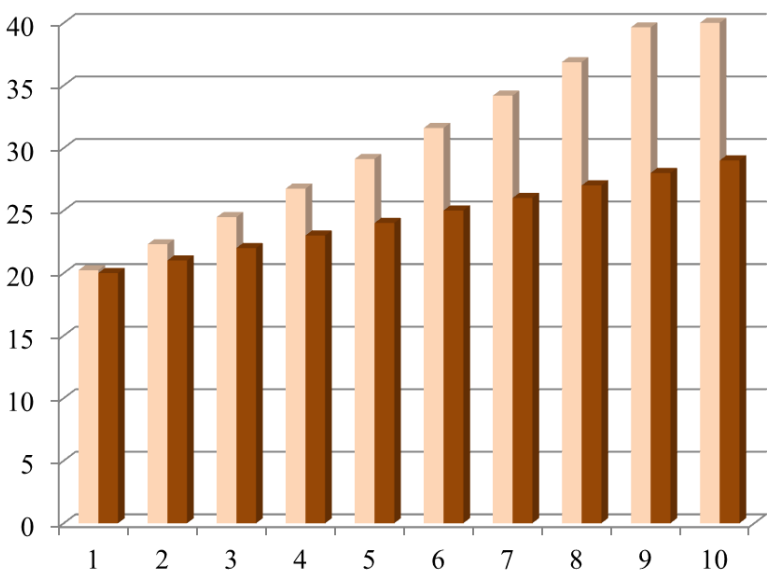

Fig. 15. The variation of the flow $Q$ in relation to the same values of diameter $D$, the same flow coefficient $\alpha$

and to the increase of pressure drop of $\Delta p=3$ bar

Theoretically, the flow rate through a flow control valve varies linearly with the size of the passage surface. However, it is basically corrected with a value due to the viscous friction of the hydromotor agent during the flow.

\section{CONCLUSIONS}

The paper presents a constructive-functional analysis of the most important equipment for resistive regulation of the flow, as well as the advantages of how to install this equipment in the structure of hydrostatic systems.
At the same time, it is demonstrated, based on the general flow control valve equation, the need to increase the fluid flow $(Q)$ with increasing pressure losses $(\Delta p)$, doubled by increasing the diameter of the fluid passage section through the flow control valve (D).

Therefore, if the pressure decreases, then the specific volume of fluid circulated in the hydrostatic installation must increase. Under these conditions, if there is a change in internal energy, then there must be a change in temperature. Normally, the fluid temperature will drop. However, in special cases, especially at high flow rates, the temperature may remain the same or increase.

It is obvious that a flow regulation causes a significant reduction in pressure because a regulating device causes local pressure losses. The pressure losses are generally minor and the flow coefficient $\alpha$ varies in very small limits, $\alpha=0.6 \ldots 0.7$.

\section{ACKNOWLEDGEMENTS}

This work is supported by the project ANTREPRENORDOC, in the framework of Human Resources Development Operational Programme 2014-2020, financed from the European Social Fund under the contract number 36355/23.05.2019 HRD OP /380/6/13 - SMIS Code: 123847

\section{REFERENCES}

[1] Baroiu, N., Vișan, D., Ciocan, O.D., Hidrostatică și pneumatică tehnologică - Indrumar pentru laborator - format electronic, Ed. Academica, ISBN 978-606-606-007-3, 2018;

[2] Medhat, K.B.K., Hydraulic Systems Volume 1 - Introduction to hydraulics for industry professionals, CompuDraulic LLC, ISBN 978-0-692-62236-0, 2019;

[3] Indiamart, Stainless Steel Hydraulic Cartridge Valve, https://www.indiamart.com/proddetail/hydraulic-cartridge-valve2076655612.html;

[4] Gresham, R.M., The basics of hydraulic flow control, Lubrication Engineering 61(11):26-28, 2005;

[5] Schmitt, A., The Hydraulic Trainer: Instruction and Information on Oil Hydraulics, Mannesmann Rexroth, 1980;

[6] Dorr, H., Ewald, R., Hutter, J., Kretz, D., Liedhegener, F., Schmitt, A., Hydraulic Trainer, Volume 2: Proportional and Servo Valve Technology Hardcover, ISBN 3-8023-0898-0, 1986;

[7] Exner, H., Freitag, R., Geis, H., Lang, R., Oppolzer, J., Schwab, P., Sumpf, E., Der Hydraulik Trainer - Grundlagen und Komponenten der Fluidtechnik Hydraulik, Der Hydraulik Trainer Band 1, ISBN: 3802306198, 1991;

[8] Gebhardt, N., Weber, J., Hydraulik - Fluid-Mechatronik: Grundlagen, Komponenten, Systeme, Messtechnik und virtuelles Engineering, Springer-Verlag, ISBN 978-3662-60663-6, 2020.

[9] Khan, H.A., Kang, C.N., Yun, S.N., A Study on the Development of Mathematical Model of Three-stage Flow Control Valve, Journal of Drive and Control 15(2):38-45, 2018, http://dx.doi.org/10.7839/ksfc.2018.15.2.038;

[10] Kilic, E., Dolen, M., Koku, A. B., Caliskan, H., Balkan, T., Accurate pressure prediction of a servo-valve controlled hydraulic system, Mechatronics, 22(7):997-1014, 2012 